\title{
The Function Mechanism and Paths of Accountability Audit of Natural Resource Assets to Promote Ecological Civilization Construction
}

\author{
Zhaohua $\mathrm{Li}^{1}$, Danhe Liu ${ }^{1, *}$ \\ ${ }^{1}$ School of Accounting, Harbin University of Commerce, 150028, Harbin, China (Social Science Fund Planning \\ Project of Heilongjiang Province (20JYE273)) \\ * Corresponding author: 18846437856@163.com
}

\begin{abstract}
The construction of ecological civilization is related to the sustainable development of the Chinese nation, to the mission and purpose of the Party, to the high-quality development of China's economy and the modernization drive and to the ecological responsibility of China as a big country. Deepening accountability audit of natural resource assets is not only an objective requirement for promoting ecological civilization construction and high-quality economic development in the new era, but also a basic guarantee for the effective operation of ecological civilization management system. Accountability audit of natural resources assets is an important part of improving the performance evaluation and accountability system of ecological civilization. This paper analyzes the related concepts of accountability audit of natural resources assets, the factors, the role mechanism and influence degree that influence the promotion of ecological civilization construction by accountability audit of natural resources assets of leading cadres. From the perspective of system design and operation implementation, the paths of accountability audit of natural resource assets to promote the construction of ecological civilization are constructed.
\end{abstract}

Keywords: Accountability audit of natural resource assets, Ecological civilization construction, Mechanism and pathway of action.

\section{Introduction}

Accountability audit of natural resources assets is an important system to improve the performance evaluation and accountability system of ecological civilization. Since the Third Plenary Session of the 18th CPC Central Committee first proposed to "implement the audit of leading cadres' natural resources assets when they leave office". In 2015, the General Plan for the Reform of the Ecological Civilization System issued by the CPC Central Committee and the State Council also pointed out that we should actively explore the objectives, contents, methods and evaluation index system of the audit of accountability leading cadres' natural resources and assets. Later, in 2017, the CPC Central Committee and the State Council issued the Regulations on Auditing Leading Cadres' Outgoing Natural Resource Assets (Trial). Since then, the accountability audit system of natural resource assets has been carried out nationwide.
In recent years, the $\mathrm{CPC}$ Central Committee has attached great importance to ecological progress. In the report of the 19th National Congress of the Communist Party of China, it is pointed out that the construction of ecological civilization is a thousand-year plan for the sustainable development of the Chinese nation, and the audit of the accountability leading cadres' natural resources assets is an important part of the ecological civilization system. Compared with single resources environment audit, auditing of outgoing leading cadres' natural resource assets covers a more comprehensive range of areas of concern and can better meet the needs of ecological civilization construction ${ }^{[1]}$. According to the existing literature, this paper sorts out the relevant concepts of accountability audit of natural resource assets and expounds the influence factors of accountability audit of natural resource assets in promoting ecological civilization construction. Finally, this paper constructs the exit path of accountability audit of natural resource assets in promoting ecological 
civilization construction from the perspective of system design and operation.

\section{LITERATURE REVIEW}

The accountability audit of natural resource assets is an important audit method with typical Chinese characteristics $^{[2]}$. Therefore, there is no definition of accountability audit of natural resource assets in the world. Some domestic experts and scholars have defined it in China, but no consensus has been reached. Cai and $\mathrm{Bi}$ proposed that the accountability audit of natural resource assets is a product of the deep integration of environmental audit and economic responsibility audit and is a natural resource asset supervision system with Chinese characteristics ${ }^{[2]}$. The accountability audit of natural resource assets is a systematic process in which audit institutions obtain and evaluate audit evidence in accordance with laws and regulations, supervise, evaluate and verify the performance of the entrusted responsibility of leading Party and government officials for the management of natural resource assets and ecological and environmental protection, and convey the audit results to the expected users ${ }^{[3]}$. In general, different from the previous audit form of "material", the accountability audit of natural resource assets is more inclined to audit the responsibilities of "people", and it is also a system in line with the national strategic deployment.

The implementation of the accountability audit of natural resource assets is a concrete manifestation of the implementation of the national development plan and the acceleration of the construction of ecological civilization. Lin believed that the accountability audit of natural resource assets implemented the top-level design of ecological civilization construction, filled the system gap and was conducive to strengthening the implementation of responsibility and improving the situation of ineffective ecological protection ${ }^{[1]}$. Xu proposed that the audit of accountability leading cadres natural resource assets can effectively make up for the shortcomings in the supervision of China's ecological civilization system, catch the main contradiction of ecological and environmental protection and alleviate many problems caused by resource publicity and environmental externalities ${ }^{[4]}$

\section{FACTORS INFLUENCING THE PROMOTION OF ECOLOGICAL CIVILIZATION CONSTRUCTION BY ACCOUNTABILITY AUDIT OF NATURAL RESOURCE ASSETS}

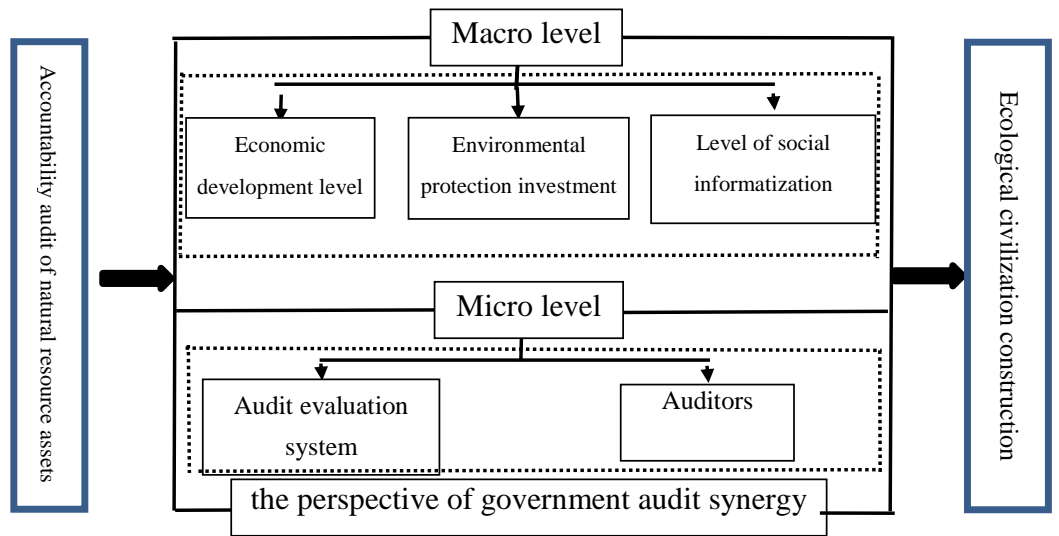

Fig.1. Analysis framework of factors influencing the promotion of ecological civilization construction by accountability audit of natural resource assets

This part analyzes the factors that influence the promotion of ecological civilization construction by accountability audit of natural resource assets from the macro, micro and from the perspective of government audit synergy. Figure 1 shows the analysis framework of the factors influencing the promotion of ecological civilization construction by accountability audit of natural resource assets.

\subsection{Influencing factors based on macro level}

\subsubsection{Economic development level}

The accountability audit of natural resource assets firmly requires local Party and government leaders to consciously consider economic and social development in conjunction with ecological progress. Sun also found through empirical research that carrying out auditing of accountability leading cadres' natural resource assets can promote high-quality economic growth ${ }^{[5]}$. Therefore, the accountability audit of natural resource assets is closely related to the construction of ecological civilization and the level of economic development.

\subsubsection{Environmental protection investment}

Since leading officials are assessed mainly on economic growth and the ecological environment, local officials' inspections of relevant enterprises and punishments for violations of laws and regulations will 
be increased. Meanwhile, it will also increase the willingness of local leaders to encourage green technology innovation in enterprises under their jurisdiction. Therefore, based on the consideration of reputation and market competitive advantages, enterprises are more willing to carry out green technology innovation, energy conservation and emission reduction, which is conducive to the effective implementation and development of national ecological civilization construction.

\subsubsection{The level of social informatization}

Nowadays, with highly developed social information, full audit coverage and comprehensive popularization of big data application technology, it is more conducive to the development and implementation of accountability audit of natural resource assets. Compared with previous environmental resource audit methods, the current analysis of natural resource assets is more in-depth, and the data obtained are more real and accurate. In addition, social informatization has enhanced the supervision function of audit. In the daily audit, audit data can be obtained in time and risks can be found, and the unreasonable use of natural resources assets can be handled in time and effectively corrected to prevent damage to the ecological environment.

\subsection{Influencing factors based on micro level}

\subsubsection{Audit evaluation system}

The audit evaluation system is an important measurement standard and basis for the accountability audit of natural resource assets. Therefore, a reasonable audit evaluation system is helpful for auditors to grasp the changes of resources and environment and the work performance of leading cadres during their tenure, so as to form a coercion mechanism for leading cadres and urge them to pay more attention to the construction of ecological civilization within their jurisdiction.

\subsubsection{Auditors}

Auditors are the backbone and key elements for the smooth implementation of accountability audit of natural resource assets. The accountability audit of natural resource assets requires auditors to be familiar with finance and resources and have relevant knowledge of resource and environment audit. In addition, auditors should have certain auditing and analysis ability of big data to adapt to the development of the current era. Therefore, when professional natural resource asset auditors are in short supply, it is necessary to improve the knowledge and ability of auditors to improve audit efficiency and quality, so as to promote the construction of ecological civilization.

\subsection{Influencing factors of accountability audit of natural resource assets from the perspective of government audit synergy}

Audit synergy mechanism. Some scholars have found that the coordination of government audit institutions with other institutions or organizations can effectively improve the efficiency of government audit, promote the realization of the "immune system" function of national audit, and ensure the effective fulfillment of the concept of government public fiduciary responsibility. Based on this perspective, the collaboration between the accountability audit of natural resource assets and other departments or organizational structures should also promote the development of the accountability audit of natural resource assets and improve the audit efficiency, so as to achieve the effect of "1+1>2".

\section{Ways to Promote Ecological Civilization Construction through accountability audit of natural resource assets}

Based on the perspectives of macro, micro and audit synergy mechanism, this paper proposes six paths conducive to strengthening the construction of ecological civilization. Figure 2 shows the analysis framework of implementation paths of accountability audit of natural resource assets to promote ecological civilization construction.

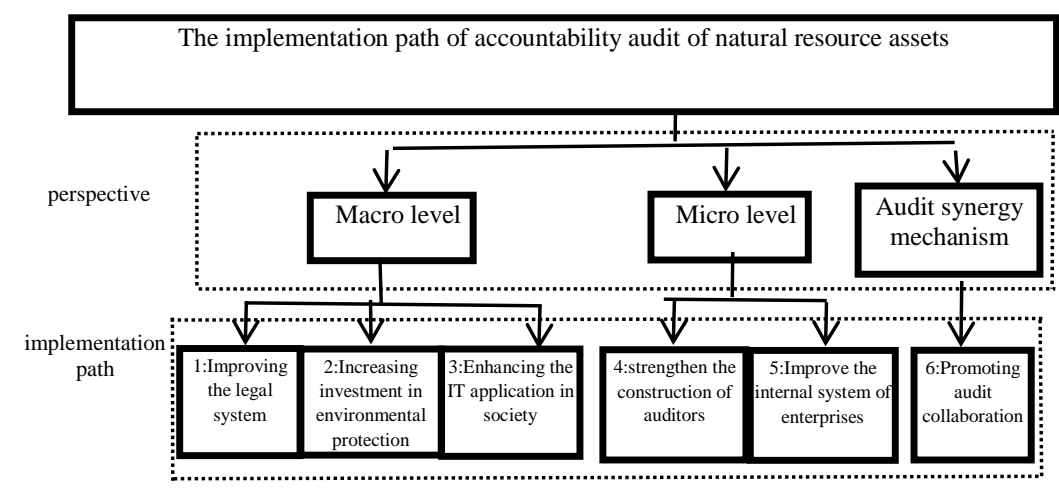

Fig.2. Analysis framework of implementation paths of accountability audit of natural resource assets to promote ecological civilization construction 


\subsection{Improving the legal system}

On the one hand, leading cadres should strengthen ideological construction. The government should strengthen the concept of leading cadres respecting, complying with and protecting nature, and establish a development concept that economic construction and natural resource protection should go hand in hand in a rational and effective way, so as to promote the development of ecological civilization at the root and promote the national strategic development. On the other hand, the construction of legal system should be strengthened. At present, the basic principle system of the accountability audit of natural resources assets exists, but the specific and operable legal rules are still in a blank state. Therefore, it is necessary to strengthen the construction of specific law implementation rules. For example, the accountability mechanism of leading cadres, the compensation system for environmental damage and the property rights system should be established and improved.

\subsection{Increasing investment in environmental protection}

Firstly, the audit fund system should be optimized. The government should attach importance to the budget management of accountability audit, so as to make reasonable use of audit funds and achieve the maximum of income. Meanwhile, attention should be paid to the allocation of audit funds, focusing on key resource projects to make full use of audit funds and improve the efficiency of audit activities. Secondly, investment in environmental protection should be increased. On the one hand, leading cadres exert pressure on local enterprises to increase their investment in environmental protection and develop green and innovative technologies, so as to tackle the root of problems caused by environmental pollution and waste of resources. On the other hand, the government should actively enact environmental protection incentive policies. Enterprises that actively carry out green innovation and respond to the national call and strictly control pollutant emissions will be rewarded to varying degrees, so as to promote the construction of ecological civilization.

\subsection{Enhancing the IT application in society}

On the one hand, modern technology should be fully utilized, whether it is "3S" technology or Global Navigation Satellite System (GNSS). At the same time, pay attention to the development trend of big data technology and integrate new technologies into audit to help auditors execute audit work efficiently and accurately. On the other hand, it is very necessary to perfect the construction of audit information platform. Natural resource asset data from different departments are input into the platform to realize the automatic analysis of audit indicators and find out audit suspects. It can also realize the national synchronous sharing of audit data through the establishment of unified standards. In addition, the audit case databases and audit models formed by various provinces and cities can also be incorporated into the audit information platform, and the contents of the accountability audit information platform for natural resource assets can be enriched through cooperation with various scientific research institutions and universities.

\section{4. strengthen the construction of auditors}

On the one hand, it is necessary to improve the status of audit discipline, strengthen the discussion of various theories and issues related to the audit of outgoing natural resource assets, expand the enrollment scale of audit in colleges and universities, and carry out higher level postgraduate education, so as to promote the development of the audit of outgoing natural resource assets. On the other hand, it is very important to improve the professional competence of auditors. First of all, it is necessary to provide targeted training for auditors at different levels and also carry out competitions, seminars, talent evaluation and other ways to strengthen personnel capacity building. Secondly, attention should be paid to the recruitment of personnel, especially those with resources, environment and big data background, so as to improve the comprehensive ability within the organization. Finally, experts in the field of environment can be hired to provide theoretical guidance, so that auditors can accurately grasp the audit focus in the audit implementation process and improve work efficiency and quality.

\subsection{Improving the internal system of enterprises}

First of all, the natural resources balance sheet should be compiled according to the principles of scientificity, comparability, operability and quantification, and the compilation system of natural resources balance sheet should be gradually improved by selecting and refining evaluation indexes according to local conditions according to the division of main functional areas. Secondly, it is necessary to improve the performance appraisal system of leading cadres by multi-dimensional improvement of economic development and natural resource assets management, so as to improve the rational use of natural assets by 
leading cadres. Finally, it is necessary to perfect the three-stage audit system, namely, in advance, in office and out of office. Before taking office, it is necessary to find out the current status of assets, and require leading cadres to make a systematic plan for the term of office and clarify their responsibilities. During the term of office of leading cadres, it is necessary to evaluate the situation of leading cadres fulfilling their responsibilities in a comprehensive and timely manner. Before leading cadres leave office, it is necessary to investigate the compliance and implementation of policies during their tenure. In addition, there will also be a post-review of the decisions made during the term of office, and accountability will be held if there are problems.

\subsection{Promote the audit coordination mechanism}

First of all, in order to smoothly promote the accountability audit system of natural resource assets, it is necessary to promote inter-departmental coordination. The audit involves a wide range of departments, including the Environmental Protection Bureau, the Land and Resources Bureau, the Water Resources Bureau, and the Agriculture Bureau. Therefore, it is necessary for various departments to coordinate and give play to the advantages of each department, so as to improve the efficiency and effect of audit. Secondly, audit supervision should be coordinated with public opinion supervision. As the power of public opinion is huge, it is necessary to apply public opinion as an auxiliary force in the accountability audit of natural resource assets to maximize the role of audit supervision. By cooperating with the professional media and organizing the media to go deep into the audit process, the power of public opinion supervision should be used reasonably and effectively to promote the progress of the audit work.

\section{CONCLUSION}

At present, the accountability audit of natural resource assets is not mature yet. It still needs to be explored and perfected for a long time. Although this paper puts forward some helpful ways to promote the construction of ecological civilization from different perspectives, there are still some shortcomings. For example, it is only a rough implementation path without in-depth expansion of each specific implementation path. In the future, it is still hoped that this article can contribute to the development of accountability audit of natural resource assets.

\section{REFERENCES}

[1] Z. Lin. AR. An Exploration on Accountability Audit of Natural Resource. 05,10-14 (2014) (in Chinese)
[2] C. Cai, M. Bi. AR. Theoretical Thinking about Accountability Audit of Natural Resource. 05, 3-9 (2014) (in Chinese)

[3] M. Liu, J. Sun. JAE. Research on Elements of Accountability Audit of Natural Resources Assets for Leading Carders. 31(04), 12-20 (2016) (in Chinese)

[4] Z. Xu, J. Chen. JAE. Improve the ecological civilization institutional system by off-office auditing of natural resources asset. 35(01), 22-24 (2020) (in Chinese)

[5] W. Sun, Y. Sun. EE. An Empirical Study on the Impact of Resource-Environment Audit on HighQuality Economic Development:A Pilot Study on the Audit of Natural Resources Assets of Leading Cadres as an Example. 36(01), 166-171 (2020) (in Chinese) 